\title{
NOTAS
}

\section{EL FUTURO DE SUBJUNTIVO EN EL ESPAÑOL CENTROAMERICANO DEL SIGLO XVIII VITALIDAD, EMPLEO E INDICIOS DE DECADENCIA*}

1. Tal vez uno de los fenómenos más estudiados en la historia de la lengua española sea el proceso de decadencia y desaparición del llamado futuro de subjuntivo, que se produce a lo largo de la Edad Moderna y contribuye a configurar -en lo que se refiere al modo subjuntivo- el sistema verbal tal y como lo conocemos hoy ${ }^{1}$.

A este respecto, se debe indicar que ya en épocas tan tempranas como el siglo XIII es posible detectar indicios de su debilidad en el sistema verbal del castellano ${ }^{2}$, aunque la práctica totalidad de los estudiosos coinciden en señalar los últimos años del siglo xv o los comienzos del siglo Xvi como el momento en que se precipita la sustitución de la forma en -re por otros tiempos indicativos y/o subjuntivos 3 : en esta

\footnotetext{
* Una primera versión de este trabajo se presentó oralmente como comunicación -con el título "El futuro de subjuntivo en el español centroamericano del siglo xviı"en el 36 Simposio de la Sociedad Española de Lingüística, celebrado en Madrid del 18 al 21 de diciembre de 2006.

${ }^{1}$ Por lo que se refiere al origen de esta forma verbal, son varias las teorías que se han mantenido a lo largo del tiempo, y que debaten si cantare deriva del futurum exactum latino o bien de una fusión de diversas formas verbales, en concreto este futurum exactum con el perfecto de subjuntivo cantauerim, o estas dos formas con el imperfecto del mismo modo cantarem; para todo lo relacionado con este tema, véase Avelino Álvarez Rodríguez, El futuro de subjuntivo del latín al romance, Universidad, Málaga, 2001, así como la bibliografía citada a lo largo de este trabajo.

2 Véanse, JuAn J. López Rivera, El futuro de subjuntivo en castellano medieval, Universidade, Santiago de Compostela, 1994, pp. 82-83 y Bruno Camús Bergareche, "El futuro de subjuntivo en español", en Indicativo y subjuntivo, ed. I. Bosque, Taurus, Madrid, 1990, p. 420

${ }^{3} \mathrm{Si}$ bien todos los autores coinciden en señalar cante como el sustituto de cantare en la mayoría de los contextos de aparición de éste, la unanimidad no es tal en el caso de la prótasis condicional, donde se propone tanto el presente de indicativo canto (Andrés Bello, Gramática de la lengua castellana, ed. R. Trujillo, Arco Libros, Madrid, 1988 [1847], p. 366; AleiXandre Veiga, "La sustitución del futuro de subjuntivo en la diacronía del verbo español", Verba, 16, 1989, p. 323 y "Las formas verbales subjuntivas. Su reorganización modo-temporal”, en Sintaxis histórica de la lengua española. La frase verbal, dir. C. Company Company, UNAM-F.C.E., México, 2006, t. 1, pp. 161-167; RoLF
}

NRFH, LVI (2008), núm. 1, 141-154 
línea, Wright analiza la aparición de construcciones contrarias a la norma preclásica, y apunta 98 casos entre 1500 y 1650 frente a 20 únicos ejemplos antes de 15004; del mismo modo, el análisis de la producción teatral de Torres Naharro demuestra, según Luquet ${ }^{5}$, que ya a principios del siglo xvi el futuro de subjuntivo no forma parte del habla de los estratos más bajos de la sociedad hispánica, por lo que cantare "se convierte a lo largo del Siglo de Oro en un rasgo de valor estilístico que refleja diferencias sociolingüísticas: caballeros y clases cortesanas lo usan, pero no así las clases populares"6.

Ahora bien, se hace necesario indicar aquí que la cronología propuesta para España no parece servir a la hora de analizar la desaparición de esta forma verbal en el continente americano, donde -en principio- se produce con mayor lentitud: en efecto, si bien Granda considera que la presencia actual del futuro de subjuntivo en determinadas zonas de América ${ }^{7}$ se relaciona con el llamado español antillano y

Eberenz, "Sea como fuere. En torno a la historia del futuro del subjuntivo español”, en Indicativo y subjuntivo, p. 390, entre otros) como el imperfecto de subjuntivo cantase (Rafael Lapesa, Historia de la lengua española, Gredos, Madrid, 1985, pp. 403-404; Rafael Cano Aguilar, "La disputada herencia de cantare", Verba, 20, 1993, 445-448; IrEnE ANDRÉs-SuÁREz, El verbo español. Sistemas medievales y sistema clásico, Gredos, Madrid, 1994, p. 268, entre otros), así como sustituciones mixtas o dobles por ambos tiempos (Emilio Alarcos Llorach, Estudios de gramática funcional del español, Gredos, Madrid, 1980, p. 68; Margarita Porcar Miralles, La oración condicional. Evolución de los esquemas verbales condicionales desde el latín al español actual, Universitat Jaume I, Castellón, 1993, pp. 132-133).

${ }^{4}$ Leavitt O. Wright, "The disappearing Spanish verb form in -re", $H, 14$ (1931), $107-114$.

5 "Sobre la desaparición del futuro de subjuntivo en la lengua hablada de principios del s. xvi", en Actas del I Congreso Internacional de Historia de la Lengua, eds. M. Ariza, A. Salvador y A. Viudas, Arco Libros, Madrid, 1988, p. 512.

${ }^{6}$ B. Camús Bergareche, art. cit., p. 421. Respecto a la relación entre el mantenimiento del uso del futuro de subjuntivo en el nivel sociolingüístico más alto y la cortesía, véase Manuel Criado del Val ("Lenguaje y cortesanía en el Siglo de Oro español: la decadencia del futuro de subjuntivo", Arbor, 1952, núm. 23, 244-252), así como las precisiones apuntadas por PierRE DE GROUlt ("La courtoisie espagnole et le subjonctif futur”, Les Lettres Romanes, 11, 1957, 73-74) y R. LAPESA (Estudios de morfosintaxis histórica del español, Gredos, Madrid, 2000, p. 852).

7 Germán de Granda, "Formas en -re en el español atlántico y problemas conexos”, Estudios lingüísticos hispánicos, afrohispánicos y criollos, Gredos, Madrid, 1978, pp. 95-117. Como es sabido, el empleo de la forma en -re parece seguir vivo en diversas zonas que rodean el mar Caribe, en concreto la región atlántica de Panamá, los departamentos de Bolívar, Santander y norte de Antioquia en la costa atlántica y el norte de Colombia, y la región de Coro en el noroeste de Venezuela, así como zonas de Cuba, Santo Domingo, Puerto Rico y Ecuador (B. Camús Bergareche, art. cit., pp. 411-412); en el caso concreto de Venezuela, el empleo de cantare es tan habitual que, según indica Ángel Rosenblat (Buenas y malas palabras en el castellano de Venezuela, Edime, Madrid-Caracas, 1956, p. 210), "usurpa frecuentemente el uso de la forma en -ra". Con todo, conviene recordar, tal y como hace VeIGA ("Las formas verbales subjuntivas...", p. 137), que "la posible conservación de las formas en -re en áreas del español americano es tema todavía necesitado de estudios en profundidad sobre el terreno", y a este 
avala, por tanto, la hipótesis de un empleo restringido y en decadencia de este tiempo verbal ya en el mismo momento en que se configura tal variedad de español de las Islas -esto es, los inicios del siglo XVI-, lo cierto es que estudios desarrollados en las últimas décadas sobre corpora de varias regiones del Nuevo Mundo obligan a replantearse este aserto y a retrasar en varios siglos la desaparición de cantare de las variantes americanas del español ${ }^{8}$.

De este modo, las investigaciones actuales demuestran claramente que el uso de esta forma verbal se verifica con gran abundancia durante los siglos XVI y XVII en regiones tan distantes como Puerto Rico, México, Santo Domingo, Ecuador, Venezuela o Chile ${ }^{9}$, así como en diversas zonas de lo que hoy constituye Argentina ${ }^{10}$; además, se hace necesario indicar que el empleo de cantare no aparece circunscrito en estos momentos a contextos de carácter formal, sino que su presencia se descubre también en otros más informales como la correspondencia familiar, y tanto en la escritura de los grupos elevados como en la de personas de escasa cultura ${ }^{11}$.

Así pues, será con posterioridad al siglo XVII cuando se produzca la decadencia y desaparición de la forma en -re en las variedades de español habladas en el continente americano: según indican diversos estudiosos ${ }^{12}$, el siglo xviII -y muy especialmente su segunda mitad-marca el final en el uso de este tiempo verbal en zonas como Chile o Buenos Aires, proceso que con algo de retraso se produce en otras más conservadoras como Uruguay o la región argentina de Santa $\mathrm{Fe}$, en la que se registran ejemplos hasta mediados del siglo XIX ${ }^{13}$; a

respecto el mismo autor señala en el trabajo citado algunas dudas sobre los casos que diversos estudiosos presentan como ejemplos de la pervivencia actual de cantare.

${ }^{8}$ A este respecto, los nuevos datos parecen dar la razón a R. EBERENz (art. cit., p. 406), quien defiende el uso general del futuro de subjuntivo en América durante los primeros siglos y una posterior extinción excepto en las zonas ya señaladas.

9 J. L. Ramírez Luengo, Breve historia del español de América, Arco Libros, Madrid, 2007, pp. 66-67; Francisco J. Zamora, "Formas en -re en documentos coloniales de Santo Domingo", RFLL, 13 (1994), p. 369; Juan P. SÁnchez Méndez, Aproximación histórica al español de Venezuela y Ecuador durante los siglos XVII y XVIII, Tirant lo Blanch, Valencia, 1997, pp. 289-290; Nelson CARTAGENA, Apuntes para la historia del español en Chile, Academia Chilena de la Lengua, Santiago de Chile, 2002, p. 48.

${ }^{10}$ María B. Fontanella de Weinberg, "Historia del español de la Argentina", en Historia y Presente del Español de América, ed. C. Hernández Alonso, Junta de Castilla y León, Valladolid, 1992, pp. 362-363; NÉlida E. Donni de Mirande, Historia del español en Santa Fe del siglo XVI al siglo XIX, Academia Argentina de Letras, Buenos Aires, 2004, p. 100.

${ }^{11}$ M. B. Fontanella de Weinberg, El español de América, MAPFRE, Madrid, 1992, p. 75.

12 Consúltense, M. B. Fontanella de Weinberg, El español bonaerense. Cuatro siglos de evolución lingüística (1580-1980), Hachette, Buenos Aires, 1987, pp. 71-72, y N. CARTAGena, op. cit., p. 48.

13 Véanse, J. L. Ramírez Luengo, "El futuro de subjuntivo en la Banda Oriental del siglo xviII”, RFLL, 20 (2002), p. 315, y N. E. Donni DE Mirande, op. cit., pp. 304-305. 
partir de este momento, por tanto, la situación del español americano es a este respecto semejante a la actual, y se caracteriza por la práctica desaparición de cantare de todas sus variedades a excepción de zonas muy concretas que rodean al Mar Caribe ${ }^{14}$.

2. A la luz, pues, de los datos expuestos con anterioridad, se hace del todo evidente la importancia que posee el siglo XviII para la historia del futuro de subjuntivo en las variedades americanas de la lengua española, habida cuenta de que es en este período cuando se produce su desaparición del sistema. Precisamente para contribuir a la descripción de la forma en -re en este momento histórico, el presente trabajo va a analizar su empleo en el español de Centroamérica, a fin de comprobar si los datos de esta región concuerdan con lo que ahora sabemos sobre otras áreas del continente ${ }^{15}$.

Con este propósito se ha analizado un conjunto de diecinueve documentos centroamericanos datados entre 1703 y 1758 que provienen de los territorios de la antigua Audiencia de Guatemala, en concreto de lo que hoy constituyen las repúblicas de Guatemala, El Salvador, Honduras y Nicaragua; tales documentos se encuentran actualmente en el Archivo General de Indias, y tanto su ubicación específica como su transcripción filológica se pueden consultar en mi trabajo, "Materiales para la historia de la lengua española en Centroamérica: algunos documentos dieciochescos, 1703-1758"16.

${ }^{14}$ Para lo que tiene que ver con el empleo de cantare en el español caribeño -en concreto, venezolano- de la primera mitad del siglo xix, véase J. L. RAMírez LuENGO, "Notas sobre el futuro de subjuntivo en la primera mitad del siglo xıx: el caso de Bolívar”, Estudios Lingüísticos de la Universidad de Alicante, 2001, núm. 15, 393-405.

${ }^{15}$ Es ya casi tópico hablar del estado de abandono en que se encuentra el estudio del español centroamericano, que constituye una de las zonas menos analizadas de todo el mundo hispánico; a este respecto, son todavía válidas las palabras de JuAN M. Lope Blanch (El español de América, Alcalá, Madrid, 1968, p. 89), quien indicaba que "el español de Guatemala es una de las modalidades peor conocidas hasta ahora, y no hay indicios de que esta situación vaya a cambiar en un futuro próximo”, aserto que fácilmente se puede ampliar a toda América Central. Felizmente, de un tiempo a esta parte se han publicado algunos trabajos que se centran en estas variedades, tanto desde un punto de vista sincrónico (entre otros, Miguel A. Quesada Pacheco, "El español de América Central”, Manual de dialectología hispánica. El español de América, dir. M. Alvar, Ariel, Barcelona, 1996, pp. 101-115) como diacrónico (entre otros, M. A. QuesAdA Pacheco, El español colonial de Costa Rica, Universidad de Costa Rica, San José de Costa Rica, 1990; María E. Nieto, El español de Honduras en el período colonial, Universidad Nacional Autónoma de Honduras, Tegucigalpa, 1995; J. L. Ramírez Luengo, "Para una historia del español en Guatemala: notas sobre historia externa en el siglo xviII", en Res Diachronicae Digital 3: Estudios sobre el siglo XVIII, coords. M. Fuertes Gutiérrez, M. J. García Folgado y J. L. Ramírez Luengo, 2004, pp. 153-170 [en red: www.resdi.com, 3]; Nuria Polo Cano, "Algunos indigenismos léxicos en el español de Guatemala del siglo XVIII", en Res Diachronicae Virtual 4: El contacto de lenguas, coords. A. García Lenza y A. Rodríguez Barreiro, 2005, pp. 185-202 [en red: www.resdi.com, 4]).

16 Aparecido en Ámbitos, 2006, núm. 15, 101-117. Véase este trabajo para los criterios de transcripción que se han utilizado en la edición de los textos, así como una 
Habida cuenta de la importancia que la tipología textual adquiere en la utilización de la forma cantare, no está de más decir que la mayoría de los documentos analizados pertenecen a lo que Oesterreicher ${ }^{17}$ denomina el "universo de los discursos jurídico-administrativos", es decir, documentación de tipo oficial generada por la administración colonial -si bien se puede señalar, dentro de ella, la presencia de tipos diversos como memoriales, cartas de poder, certificados y traslados de testimonios-, a lo que se suma también un conjunto de cartas privadas de tono formal intercambiadas entre particulares; se trata, en todo caso, de documentos "caracterizados por un alto grado de formalidad que poseen, además, una fuerte tradición retórica, todo lo cual ha de redundar indudablemente en el tipo de lengua que se emplea en ellos, de carácter culto-estándar" 18 , por lo que tal circunstancia se deberá tener en cuenta en las conclusiones que se extraigan de este análisis.

3. Una primera aproximación a los documentos en cuestión demuestra que, al igual que ocurre en otras regiones del continente como Venezuela, Ecuador, Santo Domingo, Argentina o Uruguay ${ }^{19}$, el español centroamericano del siglo XviI hace también uso del futuro de subjuntivo, que mantiene aún su vitalidad dentro del sistema verbal de la época; de hecho, los porcentajes de empleo de las diversas formas subjuntivas demuestran que este tiempo, pese a ser el menos utilizado de todos los de este modo, tiene aún una presencia abundante en la documentación, al equivaler al 16'8\% del total (Tabla 1).

Parece posible sostener, por tanto, a la luz de estos datos que cantare es en esta época un elemento vivo en el español centroamericano, y que presenta, así, una situación muy diferente de la que posee hoy en día, caracterizada por un alto grado de fosilización; esta primera conclusión aparece refrendada por el estudio por separado de su empleo en los usos libres (o no formularios) y en aquellos más

descripción general de éstos; es necesario indicar, además, que esta antología ha servido de base para algunos estudios previos, como por ejemplo J. L. RAMírez LuENGO, "Contribución a la historia del español de Honduras: edición y estudio de documentos hondureños del siglo xviıI", ALM, 42 (2004), 51-75; "Aproximación al español de Guatemala en el siglo xvirI: algunas características fonético-fonológicas”, LexisL, 30, 2006, 259-272, o Cristina Pérez Cordón y J. L. Ramírez Luengo, "El español de Guatemala en el siglo xvin: un memorial de un criollo", en El español en sus textos: $M a-$ nual de comentarios lingüisticos y filológicos, eds. C. Pérez Cordón y J. L. Ramírez Luengo, Axac, Lugo, 2007, pp. 99-108.

17 W. Oesterreicher, "Textos entre inmediatez y distancia comunicativas. El problema de lo hablado escrito en el Siglo de Oro", en Historia de la lengua española, coord. R. Cano Aguilar, Ariel, Barcelona, 2004, p. 738. p. 121.

${ }^{18}$ J. L. Ramírez Luengo, "Materiales para la historia de la lengua española...",

${ }^{19}$ J. P. SÁnchez MÉndez, op. cit., p. 290; F. J. Zamora, art. cit., p. 369; B. FontANELla DE WEInBerg, El español bonaerense..., p. 71; J. L. RAMírez LuEngo, "El futuro de subjuntivo en la Banda Oriental...”. 
rutinizados que dan lugar a las diferentes fórmulas notariales y/o epistolares (Tabla 2$)^{20}$.

TABLA 1

Porcentaje de uso de las formas de subjuntivo

(Centroamérica)

\begin{tabular}{lcc}
\hline Forma & Casos & Porcentaje \\
\hline Presente/Perfecto & 147 & $65^{\prime} 04 \%$ \\
Imperfecto/Pluscuamperfecto & 41 & $18^{\prime} 14 \%$ \\
Futuro/Perfecto & 38 & $16^{\prime} 8 \%$ \\
$\quad$ TotaL & 226 & $100 \%$ \\
\hline
\end{tabular}

TABLA 2

Porcentaje de uso de las formas de subjuntivo (usos libres/rutinizados)

\begin{tabular}{lll}
\hline Forma & Usos libres & Usos rutinizados \\
\hline Presente/Perfecto & $127\left(62^{\prime} 56 \%\right)$ & $20\left(866^{\prime} 95 \%\right)$ \\
Imperfecto/Pluscuamperfecto & $41\left(20{ }^{\prime} 19 \%\right)$ & $0(0 \%)$ \\
Futuro/Perfecto & $35(17,24 \%)$ & $\left.3(13)^{\prime} 04 \%\right)$ \\
$\quad$ ToтAL & $203(100 \%)$ & $23(100 \%)$ \\
\hline
\end{tabular}

En este caso concreto, los datos parecen demostrar que el porcentaje de empleo del futuro de subjuntivo no sólo no decrece en los usos no formularios, sino que incluso aumenta levemente, lo que pone de manifiesto que el uso de esta forma verbal no está circunscrito a contextos de tipo rutinario, sino que puede aparecer en todas las partes que componen el documento, y da idea, así, de su vigencia en el español dieciochesco de Centroamérica.

${ }^{20}$ La necesidad de distinguir entre usos libres y rutinizados en el estudio de la documentación notarial ha sido señalada ya en múltiples ocasiones, habida cuenta de que el marcado peso de la tradición que lleva aparejado el formulismo notarial -entendido como una "estructura de significado fijo sin variación en sus formantes funcionales (o con variación sinonímica) que se repite de forma sistemática en una parte específica de una tipología textual específica a lo largo de un lapso temporal más o menos amplio" (J. L. Ramírez Luengo, "Notas sobre el futuro de subjuntivo en la Vizcaya bajomedieval”, en Actas del V Congreso de Lingüistica General, ed. M. Villayandre Llamazares, Arco Libros, Madrid, 2004, t. 3, pp. 2325)- lo dota de unas características particulares que desaconsejan analizarlo conjuntamente con las partes no rutinizadas del texto; el interés del análisis diferenciado de ambos tipos de usos queda patente, por ejemplo, en J. L. Ramírez Luengo, "Notas sobre el futuro de subjuntivo..." y "Sobre la decadencia del participio en - udo en castellano: los datos de la Vizcaya bajomedieval”, Moenia, 2007, núm. 13, en prensa. 
En línea con lo anterior, la aplicación del índice de rutinización ${ }^{21}$ a los datos extraídos del corpus evidencia también la vitalidad que la forma en -re posee aún en el siglo XVIII, al presentar un índice muy bajo, de apenas el 7’89\%, según se descubre en la Tabla 3:

TABLA 3

Índice de rutinización de las formas del modo subjuntivo

\begin{tabular}{|c|c|c|}
\hline Forma & $\begin{array}{c}\text { Casos rutinizados } \\
\text { Totales }\end{array}$ & $\begin{array}{l}\text { Índices de } \\
\text { rutinización }\end{array}$ \\
\hline Presente/Perfecto & $20 / 147$ & $13^{\prime} 60 \%$ \\
\hline Futuro/Perfecto & $3 / 38$ & $7 ’ 89 \%$ \\
\hline Imperfecto/Pluscuamperfecto & $0 / 41$ & $0 \%$ \\
\hline TотAL & $23 / 226$ & $10^{\prime} 17 \%$ \\
\hline
\end{tabular}

Tal y como se desprende de la Tabla anterior, frente al empleo más o menos abundante del presente de subjuntivo en estructuras rutinizadas -en 20 de los 147 casos, esto es, en un 13'60\% del total-, el futuro de subjuntivo ofrece únicamente tres apariciones en este tipo de contextos fijos, lo que hace que en algo más de un $82 \%$ de sus apariciones su elección no esté determinada por la presencia de un formulismo notarial o epistolar.

Parece, pues, evidente que esta constatación, en unión a los datos que se extraen de las Tablas 1 y 2, demuestra sin ningún género de dudas la vitalidad de este tiempo verbal en el español centroamericano del siglo XviII: tanto su frecuencia de empleo relativamente alta como su concentración preferente en contextos no determinados por la tradición constituyen argumentos a favor de la vigencia y el empleo de cantare en la diatopía y la sincronía que se están analizando, o -al menos- en algunos de sus niveles sociolingüísticos y registros diafásicos.

Por otro lado, y en relación con este último punto, es necesario señalar que el futuro de subjuntivo no hace su aparición exclusivamente en los documentos oficiales, sino que es también utilizado de manera frecuente en las cartas privadas - de tipo formal- que forman parte del corpus: en efecto, tanto en los textos notariales como en los epistolares el porcentaje de cantare es muy semejante, de en torno al $17 \%$ de las formas de subjuntivo -en concreto, $16{ }^{\prime} 66 \%$ en la documentación notarial y 18 ' $18 \%$ en las cartas-, lo que parece demostrar que en estos

${ }^{21}$ Se entiende por índice de rutinización "el porcentaje de apariciones formularias de determinado elemento sobre el total de tales elementos en el corpus analizado" (J. L. RAmírez Luengo, "Contribución al estudio de la fórmula notarial en el castellano de la Baja Edad Media [siglos xIv-xv]", Cadernos do CNLF, 2004, núm. 8, p. 36; en red: www.filologia.org.br/viiicnlf/anais/caderno06-03.html); su utilidad en el estudio de la documentación de tipo notarial se descubre, entre otros trabajos, en RAmírez LuENGO ("Sobre la decadencia del participio en -udo..."). 
momentos el uso de esta forma verbal no está determinado tipológicamente, es decir, que su empleo no constituye una peculiaridad propia y característica de la documentación administrativa y/o jurídico-notarial, tal y como ocurre actualmente 22 .

Por lo que toca a lo estrictamente geográfico, un estudio más detallado de las diferentes áreas que componen América Central demuestra una situación muy semejante en los diferentes territorios (Tabla 4) ${ }^{23}$ :

TABLA 4

Uso de cantare por país

(usos totales/libres)

\begin{tabular}{lcc}
\hline País & Usos totales & Usos libres \\
\hline Guatemala & $30\left(20^{\prime} 40 \%\right)$ & $29\left(20{ }^{\prime} 86 \%\right)$ \\
Nicaragua & $2\left(9^{\prime} 09 \%\right)$ & $1\left(6^{\prime} 66 \%\right)$ \\
Honduras & $4\left(18^{\prime} 18 \%\right)$ & $4(25 \%)$ \\
El Salvador & $2\left(5^{\prime} 71 \%\right)$ & $1\left(3^{\prime} 03 \%\right)$ \\
\multicolumn{1}{r}{ TotAL } & 38 & 35 \\
\hline
\end{tabular}

Los datos inmediatamente expuestos indican, por lo tanto, que el uso de cantare no está circunscrito en esta época a una región específica, sino que se da de forma general en toda Mesoamérica, con unas variaciones en cuanto a su porcentaje de empleo que tienen relación no tanto con la diatopía como con los textos estudiados en sí, cuyas referencias temporales mayoritarias -futuras o pasadas- conllevan un uso más o menos abundante de este tiempo verbal ${ }^{24}$.

${ }^{22}$ Alberto Zuluaga, "El futuro de subjuntivo. Observaciones sobre la distinción lengua hablada/lengua escrita y el verbo español", en Actas del VII Congreso Internacional de Hispanistas, ed. G. Bellini, Bulzoni, Roma, 1982, t. 2, p. 1078; Goedele DE STERCK, Registros y áreas geográficas en lingüística. Valores de las formas verbales en -ra, -se, -ría y-re, Universidad, Salamanca, 2000, pp. 269-270. Nótese, además, que los tres únicos ejemplos en los que el futuro de subjuntivo es parte de una fórmula rutinizada se descubren en la documentación notarial, de manera que las apariciones de este tiempo en los textos epistolares no parecen estar determinadas por la tradición, sino que corresponden a lo que se ha denominado aquí usos libres-entendidos como un empleo vivo y no mediatizado por un contexto que exige obligatoriamente su presencia-, lo que una vez más parece constatar la vitalidad de cantare en el español centroamericano de esta época.

${ }^{23}$ En este caso, los porcentajes que se recogen junto al número de ocurrencias de cada zona se refieren al tanto por ciento que representa cantare sobre el total de formas subjuntivas que aparecen en los documentos de ese país, de ahí que la suma total no equivalga al $100 \%$.

${ }^{24}$ En concreto, los memoriales suelen referir por lo general sucesos acontecidos en momentos pasados, de manera que son menos proclives a la aparición de la forma verbal aquí estudiada, mientras que otros tipos documentales-como, por ejemplo, las cartas de poder- muestran una presencia mayor de referencias futuras y, por ende, ofrecen más ocasiones para que cantare sea utilizado. 
En cuanto a su distribución sintáctica, los datos del corpus aquí estudiado se revelan de gran interés para describir de forma un poco más precisa la situación en que se encuentra el futuro de subjuntivo en el sistema verbal del español centroamericano de la época; los 38 ejemplos registrados se descubren, así, en los siguientes contextos de aparición (Tabla 5):

TABLA 5

Uso de cantare por contexto sintáctico (usos totales/libres)

\begin{tabular}{lcc}
\hline Estructura & Usos totales & Usos libres \\
\hline Oración de relativo & $35\left(92^{\prime} 10 \%\right)$ & $32(91 ' 42 \%)$ \\
Prótasis condicional & $2\left(5^{\prime}, 26 \%\right)$ & $2(5,71 \%)$ \\
Oración temporal & $1\left(2^{\prime} 63 \%\right)$ & $1(2,85 \%)$ \\
\multicolumn{1}{c}{ ToTAL } & $38(100 \%)$ & $35(100 \%)$
\end{tabular}

Es evidente, por tanto, que en esta época existe un contexto privilegiado para el uso de cantare, la oración de relativo, que acapara la práctica totalidad de las apariciones de esta forma verbal: en concreto, el 92 ' $10 \%$ si se considera la totalidad de los casos, y un porcentaje levemente inferior -el 91'42\% - si sólo se presta atención a aquellos ejemplos que se registran en expresiones no rutinizadas; de este modo, estos datos ofrecen una notable coincidencia con los que se descubren en estos momentos en otras áreas del continente como el Uruguay25, y corroboran, así, las apreciaciones de Eberenz ${ }^{26}$, quien señala la oración relativa como el contorno sintáctico en el que el futuro de subjuntivo perdura durante más tiempo ${ }^{27}$ :

(1) Doy feé y verdadero Testimonio á los Señores que la presente vieren (doc. 4.1; El Salvador, 1719).

(2) Zertificamos En deuida forma de derecho a los $\mathrm{ss}^{\mathrm{res}}$... que la Prezente Vieren (doc. 2.3; Nicaragua, 1722).

(3) A todo lo demas que fuere del Real Seruicio (doc. 3.2; Honduras, 1742). p. 311.

${ }^{25}$ J. L. Ramírez Luengo, "El futuro del subjuntivo en la Banda Oriental...",

${ }^{26}$ Art. cit., p. 405.

${ }^{27}$ Hasta mediados del siglo Xvir según este autor $(i d$.$) , aunque es evidente que$ en el caso de América es necesario retrasar esta cronología un siglo más. Dejando de lado las fechas, es especialmente importante hacer hincapié en la idea propuesta por el hispanista suizo de que "el futuro de subjuntivo no fue retrocediendo simultáneamente en la distintas clases de subordinadas, sino en algunos casos con un notable desfase cronológico" (p. 402), perspectiva que queda perfectamente reflejada en la documentación y que permite entender de forma más clara el proceso de decadencia de esta forma verbal. 
Junto a la oración de relativo, son otras dos las estructuras en que también se mantiene cantare en la época, si bien con unos porcentajes muy inferiores que demuestran el carácter residual de estos usos: en concreto, dos únicos casos en la prótasis condicional -que corresponden a un 5'26\% de los casos- y un ejemplo aislado en la oración temporal, equivalente a un bajísimo 2' $63 \%$ del total28.

(4) Manifesto el susodicho desde luego que fuere seuido a El exercicio (doc. 1.1; Guatemala, 1703).

(5) Si sobre dhas Cobransas qualquier cosa o parte d ellas fuere nesesario contender en Juicio (doc. 1.3; Guatemala, 1719).

(6) An de Sobrebenir si En la observancia de las constituciones se pusiere todo el cuidado (doc. 1.5; Guatemala, 1755).

Así pues, se puede aplicar a Centroamérica la descripción que se ofrece en otro trabajo sobre la situación de la forma en -re en el Uruguay dieciochesco: "el uso de la forma cantare se reduce prácticamente a un único contorno sintáctico, la oración de relativo, con apariciones aisladas -y puramente marginales- en otras estructuras"29; más allá de la descripción en sí, lo que es más interesante de tal estado de cosas es la coincidencia de situaciones en áreas geográficas tan alejadas y tan dispares históricamente, algo que parece favorecer la hipótesis de un proceso de sustitución del futuro de subjuntivo semejante en cuanto a su forma y su ritmo en todo el continente ${ }^{30}$.

Con todo, y a pesar de que los datos expuestos evidencian que este tiempo verbal es aún en el siglo XviII un elemento vivo en el español centroamericano, no se puede ocultar que otra serie de factores permiten vislumbrar ya cierta debilidad de esta forma en el sistema y anuncian, así, el proceso de decadencia que le va a afectar posteriormente; de este modo, a la fuerte restricción sintáctica que presenta en estos momentos -y que por sí misma anuncia el proceso de decadencia mencionado ${ }^{31}$, se suman ciertos aspectos, como la aparición de otras

\footnotetext{
${ }^{28}$ Nótese, por otro lado, que este único ejemplo de cantare en oración temporal se data en 1703, es decir, no sólo constituye un caso aislado sino que además aparece muy en los comienzos del siglo xvin, lo que refuerza su carácter de uso decadente en la Centuria Ilustrada.

${ }^{29}$ J. L. Ramírez Luengo, "El futuro de subjuntivo en la Banda Oriental...”, p. 312. De hecho, es de destacar que no sólo la situación esbozada sino también los porcentajes de uso del futuro de subjuntivo son muy similares a los que se registran en la Banda Oriental de la época, en torno al 18\% (p. 310).

${ }^{30}$ Evidentemente, se deberá comprobar lo acertado de esta idea con estudios parciales que, siguiendo la misma metodología, se centren en el análisis de otras zonas americanas.

${ }^{31}$ De hecho, estas importantes restricciones sintácticas que cantare muestra desde
} 
formas verbales en los contextos previamente reservados a cantare, o el empleo de éste para la expresión del pasado, en la que históricamente no puede aparecer.

Por lo que toca al primero de estos fenómenos, hay que señalar la presencia en el corpus de una serie de ejemplos en los que el futuro de subjuntivo parece haber sido sustituido por otras formas verbales, en concreto el presente de indicativo -en el caso de la prótasis condicional-, el pretérito de subjuntivo y, de forma más abundante, el presente de este modo $^{32}$, tal y como manifiestan, entre otros, los siguientes casos:

(7) Les doi este poder para que recauden y Saquen todos y qualesquier papeles de... qualesquier harchibos ofisios y secretarias donde pararen o de poder de qualesquiera personas que los tengan (doc. 1.3; Guatemala, 1719).

(8) Hagan todos los demas autos y diligensias Judisiales y extraJudisiales que combengan (doc. 1.3; Guatemala, 1719).

(9) Sobre las Vtilidades, ô Perjuicios que puedan seguirsse si VM. condesziende En la Pretencion (doc. 1.5; Guatemala, 1755).

(10) Se dé quenta separadamente de lo que occurriese (doc. 3.5; Honduras, 1750).

Este proceso de sustitución lingüística se hace aún más claro en el caso de las fórmulas notariales y epistolares de la documentación, que demuestran que un mismo uso rutinizado, empleado en un contexto común y con un significado semejante, puede presentar, sin embargo, alternancia entre el presente y el futuro de subjuntivo (ejemplos 11, 12 y 13$)$ :

(11) A todo lo demas que fuere del Real Seruicio (doc. 3.3; Honduras, 1742).

(12) Para esecutar quantto sea del Real Servicio (doc. 3.4; Honduras, $1750)$.

sus mismos orígenes son una de las causas que, según J. J. López Rivera (“Aproximación al futuro de subjuntivo en el sistema verbal español", en Actas del II Congreso Internacional de Historia de la Lengua Española, eds. M. Ariza y R. Cano Aguilar, Pabellón de España, Madrid, 1992, t. 1, p. 583), determinan su sustitución por otras formas del sistema verbal.

${ }^{32}$ La posibilidad de sustituir cantare por otras formas verbales se puede relacionar, de acuerdo con CAmús Bergareche (art. cit., pp. 421-423), con la "escasa utilidad e importancia de las oposiciones morfosintácticas que establecía respecto a otras formas verbales el uso del futuro de subjuntivo en los contextos en que aparece", algo que según este autor constituye una de las causas que explican el porqué de su desaparición de la lengua. 
(13) Â quanto sea del Real Servicio (doc. 3.5; Honduras, 1750).

Evidentemente, tanto los primeros ejemplos numerados del 7 al 10 como la fórmula fija rutinizada de 11,12 y 13 presentan una fuerte idea de futuridad que justifica, en principio, el empleo de cantare, por lo que la sustitución de este tiempo por otros parece ser un síntoma de su debilidad en el sistema verbal; de hecho, apariciones como las presentes se pueden documentar también en esta centuria en otras zonas como la región bonaerense y constituyen, de acuerdo con Fontanella de Weinberg ${ }^{33}$, reflejo de la decadencia que afecta al futuro de subjuntivo en estos momentos.

Por otro lado, este carácter decadente de cantare se manifiesta también -según se dijo anteriormente- en su empleo como sustituto del imperfecto de subjuntivo cantase-cantara en contextos de pasado, papel que teóricamente no puede desempeñar ${ }^{34}$; se trata, por tanto, de casos de hipercorrección que manifiestan una cierta inseguridad en cuanto al uso de este tiempo verbal, algo que se puede relacionar con el proceso de desaparición que está sufriendo en estos momentos (ejemplos 14y 15):

(14) Las quales manifesto el susodicho desde luego que fuere seuido a El exercicio de dhos empleos (doc. 1.1; Guatemala, 1703).

(15) Mando Expressamente, que todos Los que Vinieren a Reseuir el sto, Sacramento de la Confirmazion (doc. 2.3; Nicaragua, 1722).

Así pues, son varios los indicios que llevan a pensar que cantare presenta ya en estos momentos cierta debilidad en el español de Centroamérica, situación que va a determinar que en un plazo más o menos breve esta forma verbal termine por desaparecer del habla de la región, en consonancia con lo que ocurre en la práctica totalidad del mundo hispánico.

4. A la luz de todo lo expuesto en estas páginas, se pueden sintetizar una serie de conclusiones sobre la situación y el empleo del futuro de subjuntivo en el español dieciochesco de América Central.

En primer lugar, los datos demuestran que no es ya posible datar la desaparición de este tiempo verbal en el siglo Xvi, al menos en lo referente a las variedades de la lengua habladas en el Nuevo Mundo:

\footnotetext{
33 "El uso del futuro de subjuntivo en el español bonaerense (siglos XVI a XVIII)", Lingüistica, 1997, núm. 9, p. 92.

${ }^{34}$ Este fenómeno no se da de forma exclusiva en los textos centroamericanos, sino que aparece en otras muchas zonas como por ejemplo la Venezuela decimonónica, según se descubre en el epistolario de Bolívar (J. L. Ramírez LuENGo, "Notas sobre el futuro de subjuntivo...", pp. 400-401).
} 
tanto lo abundante de su utilización, con porcentajes en torno al 15\% de todas las formas del subjuntivo, como su escaso indice de rutinización -que indica un bajo empleo de esta forma verbal en fórmulas fijas y, por tanto, un alto porcentaje de usos no motivados por la tradiciónmanifiestan bien a las claras que cantare es una forma viva en esta región en fechas tan avanzadas como el siglo XviII, al menos en algunos de sus diastratos y registros; a este respecto, la región mesoamericana no hace sino confirmar lo que otros estudiosos ${ }^{35}$ han señalado ya para otras áreas del continente, como Argentina, Santo Domingo, Ecuador y Venezuela, Chile o Uruguay.

En relación con lo anterior, y como forma de precisar lo indicado más arriba, se puede decir que el corpus aquí estudiado demuestra que cantare es en estos momentos una forma de uso general, desde un punto de vista diatópico, en las diversas zonas que componen la antigua Audiencia de Guatemala (esto es, las actuales repúblicas de Guatemala, Honduras, El Salvador y Nicaragua); desde un punto de vista diafásico, en sus registros elevados, al aparecer con cierta frecuencia no sólo en textos notariales sino también en cartas privadas de tono formal, con unos porcentajes de empleo muy similares, en torno al $18 \%$.

Por otro lado, un estudio detallado de su distribución sintáctica demuestra que la forma en -re presenta en Centroamérica en el siglo XVIII unos empleos muy restringidos que se limitan prácticamente a un único contexto de aparición, la oración de relativo, en la que se registra el 92'10\% de los casos; este hecho, al igual que otros como la sustitución de cantare por otras formas verbales en estructuras donde anteriormente aparecía este tiempo o los casos de hipercorrección en los que se emplea esta forma en lugar de cantase, constituye un indicio de la debilidad que el futuro de subjuntivo presenta en el sistema verbal de la época, y sirve, junto a los otros factores indicados, para mantener la hipótesis de que el proceso de decadencia que afecta a este tiempo verbal -y que conlleva su desaparición en un momento posterior- se comienza a evidenciar ya en plena Centuria Ilustrada.

Así pues, y más allá de los datos específicos sobre la situación centroamericana, este análisis pone de manifiesto dos ideas en las que es importante volver a incidir: en primer lugar, en la pervivencia de cantare en numerosas regiones de América hasta el Setecientos, lo que obliga a retrasar doscientos años la cronología generalmente aceptada para su desaparición; por otro lado -y tal vez más importante aún-, en la coincidencia que se descubre en las formas y los ritmos que sigue la decadencia y sustitución del futuro de subjuntivo en di-

35 B. Fontanella de Weinberg, El español bonaerenese, p. 71; F. J. Zamora, art. cit.; J. P. Sánchez Méndez, op. cit., p. 290; N. Cartagena, op. cit., p. 48; J. L. Ramírez Luengo, "Notas sobre el futuro de subjuntivo..."; N. E. Donni de Mirande, op. cit., p. 181 . 
ferentes áreas del Nuevo Mundo, lo que parece dibujar un proceso general en el español americano y obliga a preguntarse -en caso de que, efectivamente, tal proceso sea común en toda América- no sólo por qué se produce la desaparición de esta forma verbal, sino también por qué en este preciso momento y por qué de forma general en la práctica totalidad del continente.

Parece evidente, por tanto, la necesidad de llevar a cabo nuevas investigaciones que den respuesta a los interrogantes aquí planteados; a la espera de tales trabajos, queden estas páginas como una llamada de atención sobre algunas líneas de análisis que se deben explorar en el futuro, así como un aporte que contribuya a escribir la historia de la lengua española en América Central.

José Luis Ramírez Luengo

Universidad de Jaén 